\title{
Pelatihan Produksi Program Berita dan Tayang Bincang untuk Televisi bagi Siswa-siswi di Madrasah Aliyah Negeri 1 Karanganyar
}

\section{The Training for the Production of News Programs and Talk Show on Television for Students at Madrasah Aliyah Negeri 1 Karanganyar}

Erwin Kartinawati*, Erna Indriastiningsih, Dahlan Susilo

${ }^{1}$ Prodi Ilmu Komunikasi Universitas Sahid Surakarta, Jl. Adi Sucipto 154 Surakarta, Indonesia

${ }^{2}$ Prodi Teknik Industri Universitas Sahid Surakarta, Jl. Adi Sucipto 154 Surakarta, Indonesia

${ }^{3}$ Prodi Teknik Informatika Universitas Sahid Surakarta, Jl. Adi Sucipto 154 Surakarta, Indonesia

\begin{tabular}{l}
\hline Info Artikel \\
\hline Diterima 07 Oktober 2020 \\
Ditelaah 30 Oktober 2020 \\
Disetujui 13 Nopember 2020 \\
Tersedia daring 31 Desember \\
2020 \\
*Penulis untuk korespondensi \\
erwinpurwasito@ gmail.com \\
\hline \\
Kata Kunci: \\
Jurnalistik, \\
MAN 1 Karanganyar, \\
Pelatihan, \\
Talk Show, \\
Televisi \\
\hline
\end{tabular}

Keywords:

Journalistic,

MAN 1 Karanganyar,

Talk Show,

Television,

Workshop

\begin{abstract}
ABSTRAK
Era digital makin memermudah manusia dalam mendapatkan informasi. Penyediaan informasi kini tidak lagi menjadi dominasi media arus utama. Masyarakat biasa kini bisa menyediakan informasi bagi publik dengan memanfaatkan media sosial dan kanal berbasis internet lainnya, misalnya youtuber, jurnalis warga, maupun para kreator konten lainnya. Namun, kemampuan memroduksi informasi yang standar dan terpenuhinya hak publik dalam mendapatkan informasi yang akurat, bertanggung jawab, dan merujuk etika belum sepenuhnya dikuasai oleh masyarakat. Pelatihan produksi program berita dan tayang bincang untuk televisi bagi pelajar ini diharapkan mampu memberikan solusi terhadap persoalan di atas. Penentuan kalangan pelajar sebagai peserta pelatihan disebabkan rasa ingin tahu dan energi mereka yang besar untuk melakukan hal-hal kreatif sehingga bisa memberikan manfaat yang lebih besar. Manfaat tidak hanya dapat dirasakan oleh para pelajar namun juga oleh masyarakat. Pelatihan dilakukan di Madrasah Aliyah Negeri 1 Karanganyar Jawa Tengah. Hasil kegiatan ini adalah siswasiswi di Madrasah Aliyah Negeri 1 Karanganyar mampu melakukan produksi karya berbasis audio visual terutama dalam bentuk program berita televisi dan tayang bincang sesuai standar penyiaran.
\end{abstract}

\section{ABSTRACT}

\begin{abstract}
The digital era makes it easier for humans to get information. Information provision is now no longer dominated by the mainstream media. Ordinary people can now provide information to the public by utilizing social media and other internet-based channels, such as YouTubers, citizen journalists, and other content creators. Unfortunately, they have not fully mastered the ability to produce standard information to fulfill the public's right to obtain accurate, responsible information, referring to existing ethics of information. This training was expected to provide solutions to the above problems. The determination of students as training participants was due to their much more significant curiosity and energy to do creative things to provide more incredible benefits. The benefits are not only for the students but can also be picked by society. The training was conducted at Madrasah Aliyah Negeri 1 Karanganyar, Central Java. As a result, the students at Madrasah Aliyah Negeri 1 Karanganyar were able to produce audio-visual based works, especially in the form of television news programs and talk shows according to broadcasting standards.
\end{abstract}

ISSN 2685-0354 (Media Online). Diterbitkan oleh Universitas Prof. Dr. Hazairin, SH. Ini merupakan jurnal bebas akses di bawah lisensi Creative Commons Atribution 4.0 International (https://creativecommons.org/licenses/by/4.0

\section{PENDAHULUAN}

Informasi menjadi komoditas utama paling diburu dan diminati saat ini. Informasi menjadi salah satu kata kunci dalam kesuksesan karena dapat digunakan sebagai salah satu alat promosi atau media branding. Informasi kini 
bisa pula menjadi komoditas yang menghasilkan uang. Kita dapat melihat menjamurnya anggota masyarakat yang kini menjadi youtuber dan jurnalis warga (citizen journalist) berjualan informasi. Masyarakat biasa dapat membuat tayangan seperti yang dilakukan oleh kru televisi di era sebelum internet hanya dengan menggunakan telepon genggam untuk merekam peristiwa dan laptop/komputer yang dilengkapi dengan software terkait.

Fenomena ini cukup menggembirakan karena menunjukkan adanya partisipasi publik dalam penyediaan informasi bagi masyarakat yang sebelumnya didominasi media massa. Implikasi positif yang dapat dipetik berupa diversity of content dan konter terhadap konglomerasi media massa. Namun, kualitas adalah persoalan yang perlu dievaluasi dari produk yang dihasilkan warga. Hal itu dapat dilihat dari sisi pengambilan gambar, kualitas konsep dan penyajian konten, hingga implementasi etika dalam produk. Sebagian besar unggahan video dari para youtuber, citizen journalist, atau warga biasa belum memenuhi standar. Banyak video yang dibuat demi menghasilkan uang semata sehingga video yang dibuat hanya untuk menarik jumlah viewer dan subscriber. Kondisi itu terjadi karena content creator tidak berlatar belakang penyiaran dan atau jurnalistik sehingga berpengaruh terhadap kualitas produk yang disebar ke masyarakat (Chadha \& Steiner, 2015; Kartinawati \& Wisudawanto, 2020). Kualitas konten produksi masyarakat perlu diperhatikan sebab media sosial sebagai media pilihan penyampai pesan oleh content creator ke publik, juga memiliki kekuatan tak kalah beda dengan media massa. Hal itu berkenaan dengan efektivitasnya dalam menyampaikan pesan dan membentuk opini publik (Zubair et al., 2019).

Tidak hanya diproduksi secara pribadi, konten berbasis audio visual banyak juga yang dikelola secara organisasi dan atau institusi. Salah satunya adalah Madrasah Aliyah Negeri (MAN) 1 Karanganyar Jawa Tengah. Sekolah tersebut kini telah memiliki studio multimedia. Studio milik MAN 1 Karanganyar telah dilengkapi dengan segala piranti untuk produksi karya audio visual dan fotografi. Melalui piranti di laboratorium, para siswa dapat berpraktik menggunakan alat yang biasanya digunakan oleh industri kreatif utamanya televisi dan rumah produksi. Laboratorium ini diperuntukkan bagi para siswa untuk mengasah keterampilan dalam bidang produksi karya audio visual. Siswa diharapkan memiliki kompetensi tambahan selain bidang pengetahuan umum dan agama. Kompetensi itu dibutuhkan melihat dunia audio visual yang tengah terjadi saat ini. MAN 1 Karanganyar memiliki channel di Youtube yang dapat dinikmati oleh masyarakat secara luas yakni MAN TV meskipun MAN ini tidak memiliki stasiun televisi yang disiarkan secara free to air layaknya televisi lain di tanah air.

MAN TV diharapkan menjadi media pendidikan sekaligus media dakwah agama Islam yang bermanfaat bagi masyarakat (umat). Oleh karena itu, konten yang diproduksi harus memenuhi unsur kelayakan agar tujuan tersebut dapat tercapai secara maksimal. Sebagian siswa telah mampu mengoperasionalkan kamera, melakukan praktik siaran langsung suatu program acara, dan juga menampilkan hasil rekaman video mereka melalui kanal Youtube sekolah. Namun, modal dasar mengenai teori tentang produksi karya audio visual belum dikuasai secara maksimal, atau masih didapat secara otodidak. Hal itu dapat dilihat dari banyaknya siswa yang masih kesulitan dalam membuat naskah berita. Naskah tidak sesuai dengan prinsip dasar jurnalistik dan kaidah teknis lainnya, seperti penggunaan formula, news value (nilai berita) dan berkenaan dengan teknik presentasi maupun teknik pengambilan gambar (video).

Kegiatan pelatihan bagi para pelajar di MAN 1 Karanganyar Jawa Tengah ini dimaksudkan untuk memberikan pengetahuan tentang produksi audio visual terutama dalam pembuatan program berita televisi dan talk show sesuai standar minim penyiaran. Standar minim penyiaran yang mengacu pada undang-undang penyiaran, pedoman perilaku penyiaran dan standar program siaran (P3SPS) telah dirumuskan banyak pihak. Selain itu, standar minimum penyiaran juga mengacu pada hal-hal teknis berkenaan dengan kualitas gambar dan narasi (Latief \& Utud, 2017). Hal itulah yang menjadi kebaruan dan pembeda dari kegiatan pengabdian kepada masyarakat ini dengan kegiatan yang dilakukan sejumlah pihak lain sebelumnya, misalnya kegiatan pelatihan jurnalistik bagi siswa Madrasah Aliyah Berambai (Anwari, 2020). Anwari (2020) memberikan pelatihan tentang cara menulis berita untuk media cetak. Sementara, kegiatan yang ditulis ini memberi pelatihan yang lebih luas yakni produksi berita televisi dan hal-hal teknis yang melingkupi. Pengabdian lainnya yang sejenis namun berbeda konten adalah kegiatan pelatihan di Pondok Pesantren Miftahul Huda Riau yaitu tidak mencakup tentang broadcast tetapi upaya menghidupkan kembali website pondok yang telah lama vakum (Nasution \& Hasan, 2019). Kegiatan lain adalah upaya meningkatkan keterampilan bagi siswa di Asahan Sumatera Utara yang berfokus pada upaya memaksimalkan majalah dinding sekolah (Harahap et al., 2019).

\section{METODE}

Pelatihan produksi program berita televisi dan talk show ini merupakan bentuk transfer keterampilan kepada para pelajar, utamanya siswa-siswi di MAN 1 Karanganyar Jawa Tengah, pada medio Maret 2020. Jumlah peserta yang mengikuti kegiatan pengabdian kepada masyarakat ini ada sebanyak 60 siswa. Metode kegiatan berupa teori dan 
praktik. Teori yang diberikan berupa dasar-dasar tentang penyiaran, praktik dasar, dan etika media. Praktik dilakukan dengan cara langsung mencoba studio siar dengan latihan membuat berita televisi, praktik membaca berita televisi, dan praktik mengelola program talk show. Evaluasi dilakukan secara langsung setiap kali praktik dilakukan. Kegiatan praktik dilakukan secara individu dan kelompok berdasar pembagian tugas (job description) dalam program atau mata acara yang dirancang.

\section{HASIL DAN PEMBAHASAN}

Tahap kegiatan pertama berupa penyampaian teori kemudian dilanjutkan dengan praktik studio. Teori yang diberikan adalah teori praktis berkenaan dengan industri penyiaran, jurnalisme, dan prospek penguasaan kompetensi dalam bidang produksi karya audio visual. Pelatihan ini sesuai dengan kompetensi yang dimiliki pengabdi yakni sebagai praktisi media sejak tahun 2003 selain sebagai pengajar di bidang jurnalistik dan media massa. Materi yang diberikan kepada siswa adalah cara membuat berita dan cara membuat program talk show di televisi. Kata televisi disebut dalam arti mewakili produk audio visual karena tayangan audio visual kini tidak hanya dapat dinikmati melalui siaran televisi tetapi juga melalui internet. Penyebaran gagasan dan produk dari MAN 1 Karanganyar menjadi lebih luas.

Peserta diberikan pemahaman mengenai definisi berita televisi, syarat dan karakter. Hal itu harus dipenuhi agar suatu tayangan dapat menjadi layak. Berita adalah sajian tentang suatu fakta, ide, atau opini aktual yang mampu menimbulkan ketertarikan dan dianggap penting bagi sejumlah besar pembaca, pendengar maupun penonton. Sehingga, fokus dari berita adalah menyajikan informasi atau peristiwa yang memiliki nilai penting sebagai bagian dari daya tarik agar orang mau membaca, menonton, mendengar berita yang disajikan tersebut (Geraldine, 2018; Wulandari, 2015). Agar dapat menarik pembaca, berita harus memiliki nilai atau unsur kelayakan yang disebut dengan news value, antara lain significance/penting yaitu kejadian yang membawa dampak bagi kehidupan orang banyak; magnitude/besaran yaitu peristiwa yang menyangkut angka-angka yang membawa arti bagi kehidupan orang banyak; timeliness/waktu yaitu berkaitan dengan hal-hal baru atau perkembangan terkini; proximity/dekat yaitu setiap kejadian atau peristiwa yang memengaruhi publik dikarenakan faktor geografis maupun emosional; prominance/tenar yaitu menyangkut hal hal terkenal atau sangat familiar bagi masyarakat; human interest/manusiawi yaitu memberi sentuhan perasaan luar biasa kepada pembaca, menyentuh hati nurani, atau tentang kehidupan para tokoh dalam situasi yang biasa dijalani masyarakat umum (Brooks et al., 2010). Para peserta sekaligus melakukan review terhadap berita yang pernah mereka buat untuk menilai apakah berita tersebut telah memenuhi unsur kelayakan.

Hal lain yang disampaikan dalam materi pelatihan adalah tentang berita televisi yang memiliki ciri dan syarat. Jurnalistik televisi adalah sajian dalam bentuk kombinasi antara penampilan, visual, verbal, teknologikal, dan dimensi dramatikal. Visual yaitu hal-hal terkait bagaimana sajian ditampilkan dalam bentuk gambar yang tajam, jelas, hidup, dan memikat. Sementara verbal berkenaan dengan bagaimana kata-kata disajikan secara singkat, padat, dan juga efektif. Teknologikal berkaitan dengan masalah teknis yakni daya jangkau siaran, kualitas suara dan gambar yang dihasilkan, serta diterima oleh pesawat televisi penerima di rumah-rumah warga. Dramatikal bersinggungan dengan aspek serta nilai dramatik yang dihasilkan oleh rangkaian gambar yang dihasilkan secara simultan. Aspek-aspek itulah yang disebut tidak ada pada media massa jenis lainnya terutama radio dan surat kabar. Mengenai aspek dramatik, televisi menggabungkan tiga kekuatan sekaligus yakni kekuatan gambar, suara dan kata-kata. Oleh karena itu, para pakar komunikasi menyatakan bahwa televisi memiliki daya hipnotis yang tinggi. Emosi dan perilaku khalayak mampu diciptakan dan dimainkan dengan hal tersebut.

Gambar dalam berita televisi merupakan kekuatan utama (Halim, 2019). Ketersediaan gambar menentukan berita atau produk bisa muncul atau tidak (Burton, 2012). Untuk menghasilkan berita televisi, pada dasarnya sama dengan membuat berita untuk jenis media lainnya (koran, radio, internet). Berita televisi tetap mengikuti struktur dan rumus yang telah ada. Hanya bentuk penyajian yang merupakan pembeda dengan jenis media lainnya. Berita televisi disajikan lebih singkat atau tidak panjang lebar karena keterbatasan durasi tayang (Latief \& Utud, 2017). Berita televisi memiliki acuan tersendiri meski secara umum tetap melekat aturan umum yang berlaku. Tiga prinsip kunci yang merupakan pedoman bahasa televisi adalah: (1) Diucapkan atau dituturkan. Naskah harus diubah menjadi bahasa tutur seperti saat seseorang berbicara dengan orang lain secara langsung; (2) Dari orang ke orang. Naskah dibuat dengan menggunakan bahasa pergaulan sehari-hari guna menambah kelancaran komunikasi antara media dan penontonnya; (3) Sinkronisasi antara gambar dan narasi. Ini merupakan pembeda antara berita televisi dengan berita jenis media lainnya. Menurut Yorke (2000), prinsip dasar naskah berita televisi tidak dapat dapat ditawar-tawar, yaitu langsung, singkat dan tepat/akurat; gunakan kalimat kalimat pendek; gunakan anak kalimat daripada menulisnya dalam kalimat 
panjang pola bertumpuk; ringkas karena apa yang kamu tulis untuk konsumsi telinga dan mata; gunakan kalimat aktif daripada pasif, gunakan kalimat-kalimat yang familiar agar orang tidak bingung dan jengah; sampaikan dengan bersemangat berapi-api namun tetap dengan tutur kata sopan.

Penjelasan di atas menunjukkan bahwa berita televisi memiliki rumus yang sama dengan berita lainnya, yaitu $5 \mathrm{~W}+1 \mathrm{H}$. Namun, satu formula tambahan untuk berita televisi adalah easy listening formula. Hal ini dikarenakan siaran berita media elektronik sifatnya sekilas (transitory) atau tidak dapat diulang. Berbeda dengan media cetak yang kapanpun dapat dibaca ulang bila tidak paham akan informasi disajikan (Latief \& Utud, 2017).

Peserta dilatih membuat program berita. Hal pertama dilakukan adalah menentukan durasi tayangan yaitu 15 menit, 30 menit, dan satu jam. Durasi dihitung termasuk dengan durasi iklan. Selain durasi, yang penting lainnya adalah konsep mata acara dan khalayak sasaran. Hal itu akan memengaruhi format atau tampilan mata acara termasuk pemilihan model presenter, gaya berbusana maupun cara membawakannya kepada khalayak/penonton. Usai pemberian materi, peserta dibawa ke ruang studio untuk praktik secara langsung tentang produksi berita televisi dan talk show (Gambar 1, Gambar 2, Gambar 3). Hal yang dilakukan para siswa adalah praktik membuat berita standar televisi, praktik membaca naskah berita televisi, dan praktik menjadi presenter berita televisi. Di bagian lain, peserta juga praktik memroduksi program talk show yang dilakukan dengan bertugas secara bergantian menjadi presenter, narasumber, kameramen, audioman, dan produser. Presenter adalah sosok pembawa mata acara, kameramen adalah kru yang mengoperasionalkan kamera, sementara produser adalah sosok yang bertanggung jawab mengenai mata acara/program.

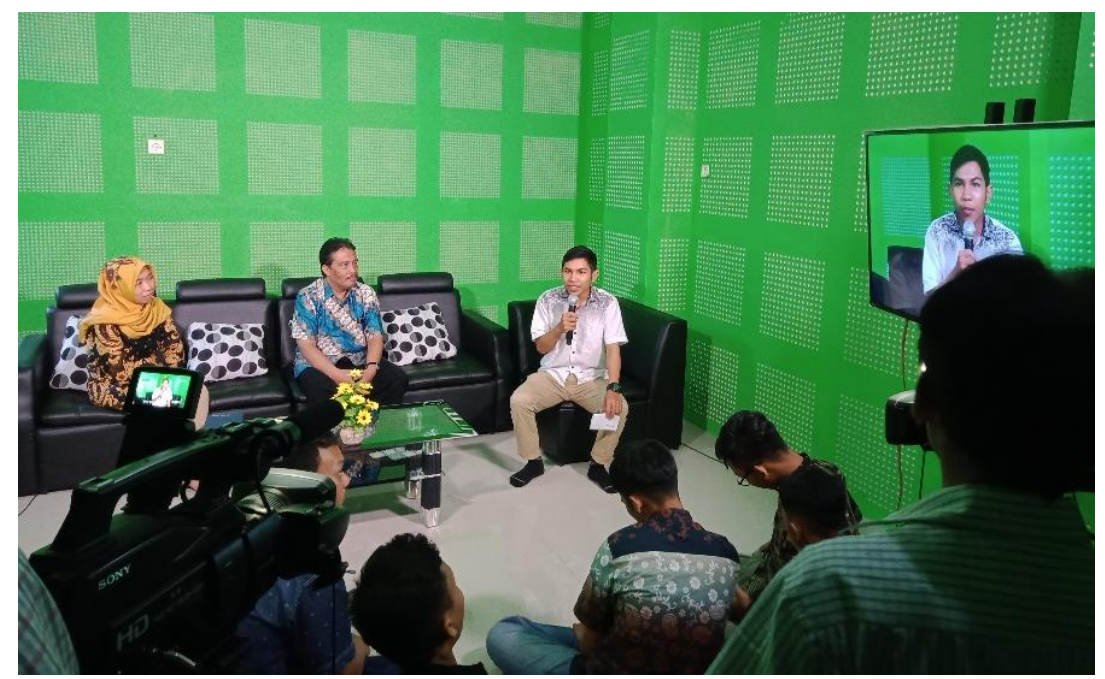

Gambar 1 Praktik produksi program talk show dalam rangkaian kegiatan pengabdian kepada masyarakat di MAN 1 Karanganyar

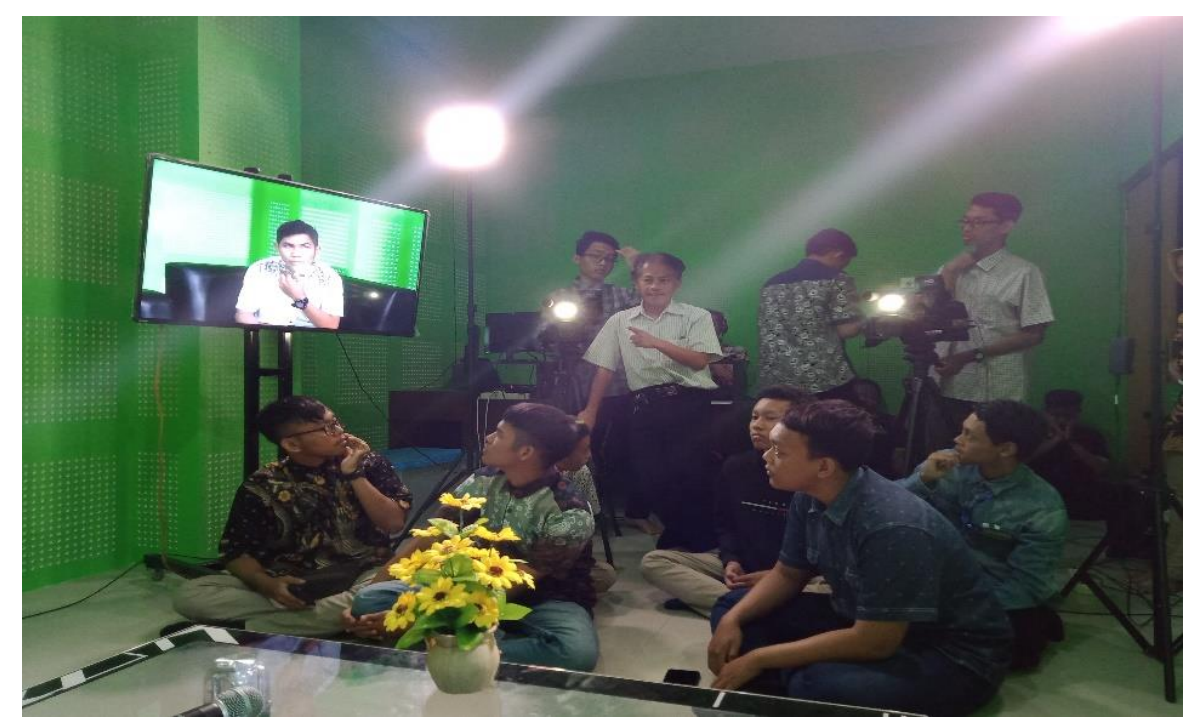

Gambar 2 Praktik menjadi kameramen, audioman, switcher, dan produser bagi para siswa MAN 1 Karanganyar 


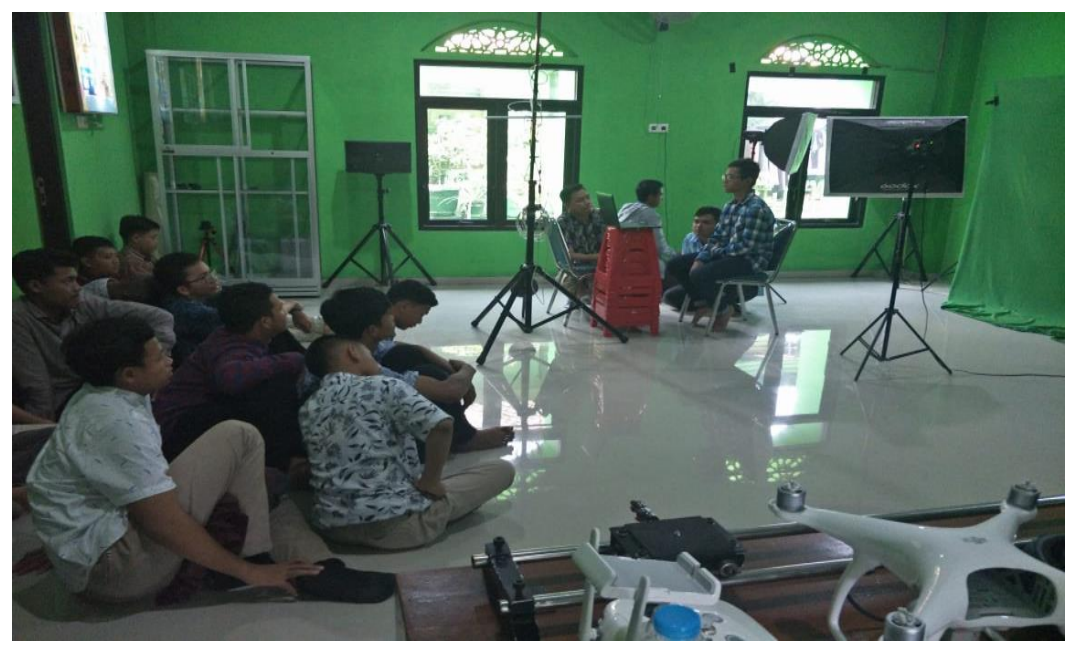

Gambar 3 Para siswa praktik membaca berita televisi dalam pelatihan broadcasting di MAN 1 Karanganyar

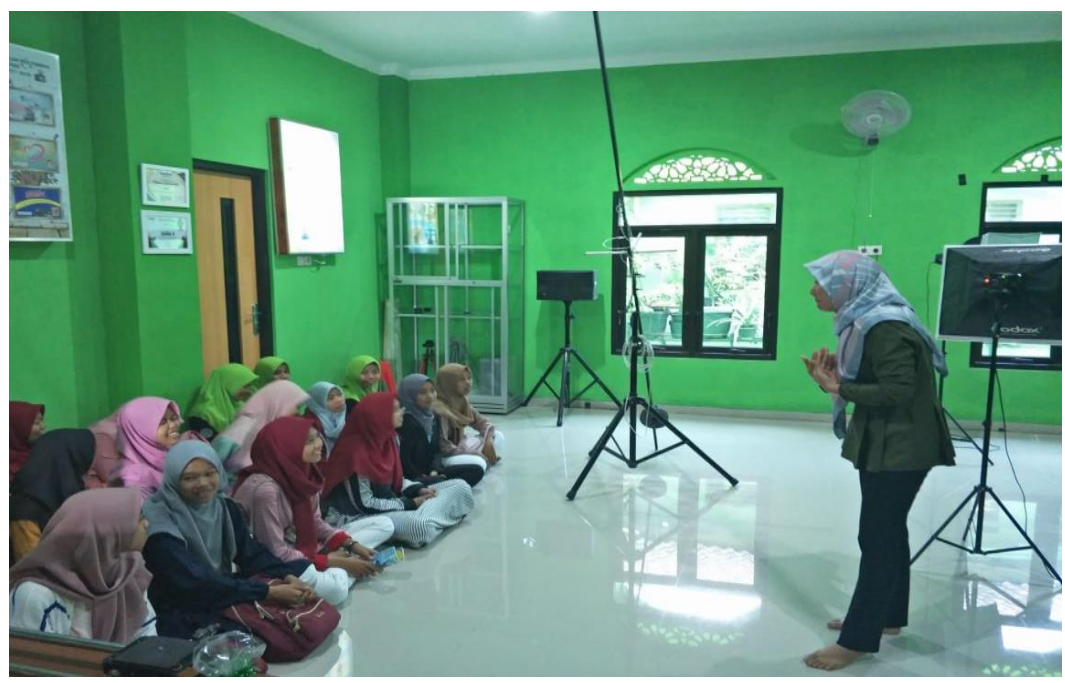

Gambar 4 Kegiatan diskusi dan evaluasi praktik pelatihan di MAN 1 Karanganyar

Hasil dari kegiatan ini adalah bertambahnya pengetahuan dan keterampilan siswa sehingga mampu membuat berita televisi sesuai standar dan mengacu etika jurnalistik dan bentuk karya produksi audio visual lainnya. Kesimpulan itu didapat berdasar keterangan pengurus laboratorium dan juga para siswa saat kegiatan berlangsung (Gambar 4). Kemampuan produksi audio visual selama ini didapat secara otodidak dan pengembangan pribadi namun teori yang berkenaan dengan jurnalisme dan penyiaran belum didapat secara langsung. Unsur kognitif dan kreativitas siswa memberikan sumbangan dalam bentuk meningkatnya kualitas produksi konten Youtube MAN 1 Karanganyar. Konkritnya, siswa menjadi lebih tahu tentang prinsip pengambilan gambar melalui kamera, cara membuat naskah berita televisi, cara membuat mata acara/program, cara menjadi presenter televisi secara profesional, dan tentang prinsip-prinsip dalam mengendalikan satu program mata acara. Peserta juga ditegaskan perihal pentingnya memerhatikan visi dan misi dalam pembuatan suatu program. Dalam setiap produksi karya, karya harus disesuaikan dengan landasan organisasi MAN 1 Karanganyar. Selain sebagai wahana pendidikan dan keterampilan, MAN 1 Karanganyar juga merupakan wahana dakwah yang diharapkan bermanfaat bagi peningkatan kualitas hidup masyarakat.

\section{KESIMPULAN}

Secara umum, tujuan dari kegiatan pengabdian ini telah tercapai yaitu peningkatan kemampuan dan keterampilan dalam bidang produksi karya jurnalistik dan talk show televisi. Pengetahuan dalam suatu proses produksi merupakan hal yang sangat penting dan mendasar. Semakin sering terjun dalam proses produksi kreatif, maka keterampilan akan terasah. Meski demikian, kontrol agar kualitas tayangan terus terjaga dan tayangan dapat memberikan manfaat bagi publik sesuai misi dan misi dari media dibuat tetap dibutuhkan. Krebilitas 
komunikator/sumber merupakan hal dan kunci utama sukses di bidang ini. Kredibilitas berkaitan dengan kualitas/bobot konten, cara penyampaian produk ke masyarakat.

Meski demikian, sangat penting bagi peserta untuk tidak puas hanya dengan melihat hasil produksi sendiri. Peserta perlu untuk terus melihat berbagai alternatif tayangan (produksi pihak lain), sebagai sarana untuk meningkatkan kualitas siaran dengan menjadikannya sebagai sumber pembanding atau sumber inspirasi produk kreatif dihasilkan sesuai dengan prinsip-prinsip penyiaran yang telah dilatihkan.

\section{DAFTAR PUSTAKA}

Anwari, R. (2020). Pelatihan jurnalistik untuk siswa kelas XI MA Darussalam Barambai. Jurnal Pengabdian Untukmu Negeri, 4(1), 107-110.

Brooks, B. S., Kennedy, G., Moen, D. R., \& Ranly, D. (2010). News reporting and writing. Bedford/St. Martin's.

Burton, G. (2012). Media dan Budaya Populer. Jalasutra.

Chadha, K., \& Steiner, L. (2015). The Potential and limitations of citizen journalism initiatives. Journalism Studies, 16(5), 706-718.

Geraldine, T. (2018). Strategi produksi tim redaksi program berita iNEWS siang untuk mencapai target rating [Skripsi]. Program Studi Televisi dan Film, Fakultas Seni Rupa dan Desain, Institut Seni Indonesia.

Halim, S. (2019). Reportase: Panduan praktis reportase untuk media televisi. Kencana.

Harahap, D. A., Nasution, W. N. A., Gulyanto, B., \& Dailami. (2019). Pelatihan peningkatan keterampilan siswa dalam membuat majalah dinding sebagai hasil jurnalistik di Asahan. Jurnal Anadara Pengabdian Kepada Masyarakat, 1(2), 141-146.

Kartinawati, E., \& Wisudawanto, R. (2020). The implementation of basic principles of journalism in citizen journalist's news on NETCJ. Jurnal ASPIKOM, 5(1), 11-26.

Latief, R., \& Utud, Y. (2017). Siaran televisi non drama: Kreatif, produktif, public relations, dan iklan (2 ed.). Kencana.

Nasution, N., \& Hasan, M. A. (2019). IBM pelatihan cms content dan digital jurnalistik. DINAMISIA -Jurnal Pengabdian Kepada Masyarakat, 3(1), 22-30.

Wulandari, T. A. (2015). Mendongkrak keberhasilan program televisi di Indonesia melalui akun pada situs jejaring sosial twitter. JIPSi: Jurnal Ilmu Politik dan Komunikasi, 5(2), 13-24.

Yorke, I. (2000). Television news (R. Alexander (ed.); Fourth). Focal Press.

Zubair, F., Bakti, I., \& Yustikasari, Y. (2019). Pemberdayaan Perangkat Desa Terampil Bermedia dalam Membangun Kesadaran dan Kepedulian Masyarakat terhadap Lingkungan di Desa Cikeruh Kecamatan Jatinangor Kabupaten Sumedang. Abdihaz: Jurnal Ilmiah Pengabdian pada Masyarakat, 1(2), 66-73. 